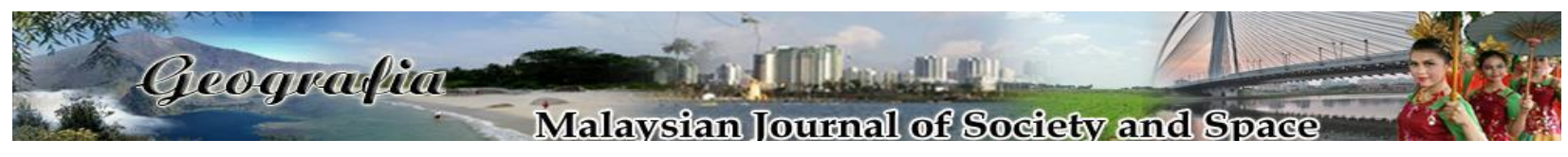

\title{
Predictive modelling of individual well-being among professional engineers
}

\author{
Norizan Baba Rahim \\ Management Section, School of Distance Education, Universiti Sains Malaysia \\ Correspondence: Norizan Baba Rahim (email: norizanbaba@usm.my)
}

Received: 09 October 2020; Accepted: 19 February 2021; Published: 27 February 2021

\begin{abstract}
Engineers have a crucial role in furthering Malaysia's technological advancements. Besides, engineers are important in creating wealth and they assist the nation in becoming an active player in the global market. They possess special knowledge and expertise and are known to be driven to climb the career ladder. However, sometimes the engineers' vision, ambition, goals, and expectations do not align with those of their employers. As a result, the conflict between being ambitious and the work demand structured by employers has affected engineers' well-being (WB). In this study, the effect between protean career orientation (PCO) [self-directed (SD) and valuesdriven (VD)] and individual WB [career satisfaction (CS) and psychological WB (PWB)] was investigated using a sample of 261 male and 126 female professional engineers (PEs) with the mean age of 42 years old. The research model was examined via the protean career theory. Partial least square (PLS) regression findings revealed that PCO (VD) positively influenced CS. Besides, PCO (SD) also positively affected PWB. Based on the findings, this research suggests that organisations perform necessary amendment to the PEs' key performance areas, for them to know that their goals and expectations are parallel with their employers'. Moreover, employers need to offer opportunities and allow the PEs to maximally utilise their skills or to grow their abilities to full potential. Consequently, PEs will have an increased level of CS and PWB.
\end{abstract}

Keywords: career satisfaction, engineers, individual well-being, SmartPLS, protean career orientation, psychological well-being

\section{Introduction}

Drastic changes in the world have impacted the engineering profession. For instance, being an expert in their field, engineers are highly ambitious and have great expectations. Since the essence of career has become different, engineers must be in charge of their career's planning and managing. Thus, protean career orientation (PCO) is a suitable mind-set to be applied in the present work setting (Hall, 2004). Engineers become architects of their career as they do not wait for their employer or the organisation they work for to direct their path. Values like freedom and 
adaptability are portrayed as the self-directed (SD) perspective in this orientation, as noted by Hall (2004). On the other hand, Buil, Martínez, and Matute (2019) have stated that handling one's career development can create numerous positive effects. The most typical career psychological consequences are catered satisfaction and well-being (WB). Nonetheless, for business needs, evaluation of engineers is conducted by the organisation, thus, increasing workload has become a part of the engineers' career. This increasing job demand has caused an adverse effect on engineers' psychological condition. Engineers face an extremely high job demand. Tight deadlines and budget constraints exist in highly competitive companies. To avoid getting penalties, the working hours are usually long (Lingard, 2019). Consequently, this scenario has increased their health problems. Most engineers suffer from constant tiredness and stress due to excessive workload. Engineers experience a significant drop in work performance because they are unable to meet their target, which eventually causes deficiencies in the final product. Besides, completion of projects becomes delayed and customer deadlines and requirements are not fulfilled (Rahim, 2017).

The engineering sector is one of the crucial engines to achieve Malaysia's economic transformation goal (Kelly Services, 2012). A RM 58 billion investment in the engineering sector was made in 2010 by the Malaysian government. The National Key Economic Area (NKEA) has targeted a 5\% annual growth from this investment from 2010 to 2020 . This sector is projected to deliver RM 131 billion in Gross National Income (GNI), as well as creating 52,300 new jobs. A major portion of these will be high-skilled jobs with approximately 21,000 jobs for skilled professionals like engineers. However, based on a survey by Job Central Malaysia's Work Happiness Survey 2013, engineers were discovered to be among the unhappy group of employees (Boo Su-Lyn, 2014). Engineers could be feeling such because of discontentment with advancement prospects, work autonomy, and work demand. This scenario becomes worse since less attention is given to the study context. Therefore, this present research intended to explore the association between PCO [self-directed (SD) and values-driven (VD)] and individual WB outcomes [career satisfaction (CS) and psychological well-being (PWB)] among professional engineers (PEs). This study's research questions are:

1. Does PCO (SD) influence CS among PEs?

2. Does PCO (VD) influence CS among PEs?

3. Does PCO (SD) influence PWB among PEs?

4. Does PCO (VD) influence PWB among PEs?

\section{Literature review}

\section{Protean Career Orientation}

Protean career orientated employees can successfully undergo a self-management activity. This activity can make them realise their full potential and achieve career success. Stauffer et al. (2019) mentioned that people with a PCO use their personal values to direct their career instead of waiting for the organisation to manage it for them. They added that PCO is a two-dimensional framework. The first dimension is SD, i.e., taking personal control over career development. With this attitude, a person would excel in performance and learning demands. Meanwhile, the second dimension is VD, i.e. the personal meaningful values and goals of the individual. It could lead a person towards 
achieving career success (Presti, Manuti \& Briscoe, 2019). VD can make an individual explore his or her goals as well as perform career decision making. With these values, individuals focus on extrinsic factors like income level, status, and promotion. This value is in line with the operant conditioning by Skinner and Thorndike indicates positive reinforcement (rewards/praise) are favourable events or outcomes that are presented after the behaviour. It is something that happens after a behaviour or event that strengthens or increases behaviour or likely to occur again. According to Hirschi, Jaensch and Herrmann (2017), the focus of a protean careerist is psychological success, besides the feeling of pride and personal triumph. In theory, countless ways exist to attain subjective success in a career, while the conventional, objective view of career success only permits for one way, i.e. the path leading to the organisation's top. Successful protean careerists have two meta-competencies, which are adaptability and self-awareness (Hall, 1976).

Hall (2002) defines competency as the comprehensive feature that allows an individual to be effective in a wider range of operation, like a job role. Meta-competency is very important since it influences the capability to gain other competencies. Based on the protean career concept, a person requires adaptability to excel in a situation in which autonomy, self-direction, and proactive behaviour are becoming more crucial, both at work and in private (Hall, 2002; Baruch et al., 2019). Nevertheless, an individual must be capable and ready to familiarise with new circumstances. Hence, two key components of adaptability are the ability (adaptive competence) and motivation (adaptive motivation) to learn. However, adaptability alone is insufficient. A fruitful quest of a protean career needs a second meta-competency, namely identity or self-awareness. Being sure of one's own values, motivation, abilities or interests is vital to determine where they want to move towards in life, to retain a sense of direction, and successfully adapt to new work conditions (Baruch et al., 2019). The significance of identity exploration for individuals in the protean career context has been emphasised by Hall et al. (2018).

Therefore, protean careerists must learn continuously. They must also look for work challenges (Hall, 2004). Combining SD and VD has resulted in four key career orientations i.e. dependent, reactive, rigid, and protean. First, having a low level in both SD and VD components is categorised as dependent career orientation. This implies that workers are not following their principles and not managing their careers. On the other hand, reactive orientated individuals manage their career. Nonetheless, their internal values are not applied as guidance. Instead, they direct their career using organisational values. Next, individuals have a rigid career orientation when they cannot shape their career. Lastly, a protean career orientated person is considered proactive and has good performance when he or she is competent in both SD and VD components (Briscoe \& Hall, 2006).

\section{Individual well-being}

Generally, communities and organisations pay attention to employees' psychological well-being. As employees spend more time at the workplace compared to their home, the workplace significantly affects their life. For example, an individual might spend about a quarter or a third of his or her life at the workplace. The work satisfaction of an employee could determine a fifth quarter of this person's life satisfaction (Mouratidis, 2018). Some working elements such as supervision and complexity might influence the employees' depression level and it has been proven by scholars that depression has contributed to the reduced production and health conditions of employees (Rahim, 2017; Berkman 1971a). It is well-matched when the workplace could stop mental illness to enhance the employees' WB. Nonetheless, the WB of the employees is also a 
concern for employers. For example, when employers are trying to generate more products and profits, they must provide a tangible benefit. Employees prefer to have a stable job with better perks. There is an interesting finding from a survey conducted among the upcoming generation of employees. The majority were found looking for personal development and a greater meaning of their career. For them, the way they look at their career is as something pleasant, satisfying, and socially beneficial (Khan et al., 2020). As reported by Hui et al. (2020), it is easy to identify the WB or happiness of an individual from a subjective perspective. Nevertheless, as suggested by some researchers, it is better to use a rigorous approach. This would prove a more complex task (Hui et al., 2020). According to academicians, there are two old philosophical orientations. The first perspective is called hedonic (Diener et al., 2018). It claims that WB is the existence of positive affect and lack of negative effect. The second perspective is widely known as eudaimonic. It states that WB does not involve maximising positive experiences. Furthermore, it concerns living fully to improve potential possibility (Lambert et al., 2020). Currently, study on individual WB has been given great attention by scholars. It has been reported that emotional WB and work satisfaction have affected several outcomes, namely citizenship at work, turnover rates, and performance ratings (Ismail \& Warrak, 2019). Many investigations on the association between individual-level job satisfaction and individual-level performance have been conducted. These studies revealed a positive relationship; specifically, satisfaction that relates with supervisor and career. Nevertheless, the direction of this relationship is yet to be completely resolved.

\section{The effect of Protean Career Orientation (SD \& DV) on career satisfaction}

Workers with a firm PCO are very proactive in developing career goals to personally manage their careers (Hall et al., 2018). Unlike those who embraced organisational goals or expect supervisors to allocate specific goals for development and performance, high protean career-orientated people generally fix unique goals and values for success (Briscoe et al., 2006; Greenhaus et al., 1990). Such people are both SD and VD to build specific goals, which allows the fulfilment of their values. Moreover, individuals with a strong PCO will probably carry out numerous career strategies to assist them in achieving these personally significant goals (Hall, 2002). Briscoe et al. (2006) explained that personal values function as the key drivers of career action, whereby these SD and VD people are presumed to guarantee the achievement of these goals (Briscoe et al., 2006). Thus, they are encouraged to form and execute tactics to attain success. Latest studies support this concept as PCO has been demonstrated to foresee engagement in networking and visibility strategies (Hall et al., 2018). As such, since protean career-orientated people are steered by internally attained career and life values, and develop their career via SD action, it is predicted that they will proactively form specific goals and strategies to accomplish them (Briscoe \& Hall, 2006). These strategies aim to assist individuals in attaining CS. Hence, PCO is predicted to impart a positive impact on CS. As such, the study hypothesized that:

$\mathrm{Hl}$ : PCO (SD) has a positive influence on CS.

$\mathrm{H} 2$ : PCO (VD) has a positive influence on CS.

\section{The effect of Protean Career Orientation (SD \& VD) on psychological well-being}

Protean career attitude comprises SD and VD behaviours (Briscoe \& Hall, 2006). It involves forming career insight and being initiative in controlling one's career. Employees with a protean 
career attitude ought to be encouraged by challenging targets and extending their capabilities, i.e. achievement. As mentioned by Hall (2004), an individual with a protean career must be highly driven to follow his or her internal compass, i.e. sustaining personal ideals or principles, instead of extrinsic motivators like money, status or promotion. This, subsequently, should intensify feelings of career success (Diener et al., 2018). Additionally, a protean careerist assesses his or her achievement according to his or her values (psychological subjective success), instead of going up the corporate ladder in the organisation (vertical objective success) (Hall, 1996). Therefore, the protean career attitude aids in feeling psychological success (Diener et al., 2018). Since not much investigation on the theoretical relationship between PCO and PWB has been carried out, hence, based on the above assumption, the study hypothesized that:

H3: PCO (SD) has a positive influence on PWB.

$\mathrm{H} 4$ : PCO (VD) has a positive influence on PWB.

Based on these testable hypotheses, the following conceptual framework was proposed for the research (see Figure 1).

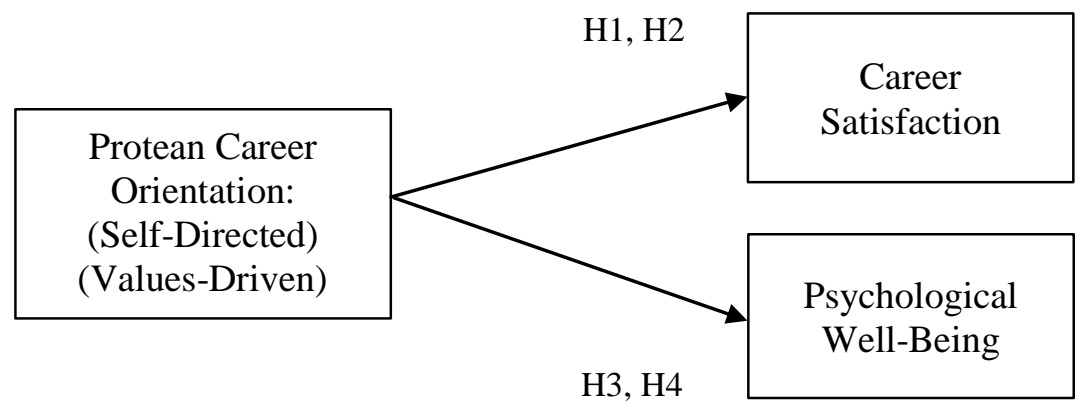

Figure 1. Research framework

\section{Method and study area}

\section{Sampling and data collection}

Data were gathered via a self-administered questionnaire. The unit of analysis was PEs registered with the Board of Engineers Malaysia (BEM). A total of 387 PEs were surveyed. The requirement for PEs is to clock in an average of 50 hours of Continuous Professional Development (CPD) activities every year to renew their practising certificate. These CPD activities are organised by the Institution of Engineers Malaysia (IEM). Besides that, IEM conducts other events like meetings, exhibitions, and visits to promote the profession of engineering. Hence, IEM was approached and the go-ahead to administer the questionnaire to PEs during their CPD activities was sought.

\section{Measures}

In general, the measures were taken from past research with acceptable reliabilities. PCO involves improved mobility, a better whole-life perspective, and a developmental progression (Briscoe et 
al., 2006). There are two dimensions i.e. SD and VD. The SD scale was applied to evaluate the level individuals believe they act autonomously in handling their career. It concerns more about career management behaviour in contrast to VD. The SD scale encompassed eight items. Sample item included "I am in charge of my own career". The second protean scale was conceived to find out the level individuals utilise personal versus external values to set career priorities and goals. It contained six items. Sample item included "I'll follow my own guidance if my company asks me to do something that goes against my values". Both PCO scales asked the respondents to specify the level the scale items are true for them via a 5-point Likert scale (1 'strongly disagree' to 5 'strongly agree'). Briscoe et al. (2006) stated that the coefficient alpha for SD and VD were 0.81 and 0.69, respectively. On the other hand, CS was evaluated via five items developed by Greenhaus et al. (1990). Respondents rated the items based on a 5-point Likert scale (1 'strongly disagree' to 5 'strongly agree'). Sample item included "I am satisfied with the success I have achieved in my career". In this research, Cronbach's alpha was determined to be 0.91. Next, to assess PWB, an eight-item index of PWB designed by Berkman (197la, 197lb) was employed. Ratings were based on a 5-point Likert scale, i.e. 1 (strongly disagree) to 5 (strongly agree). Sample item included "I often feel pleased about having accomplished something". The coefficient alpha was 0.72 .

\section{Data analysis}

SmartPLS software (Henseler, Ringle \& Sinkovics, 2009), via the Structural Equation Model (SEM) from Partial Least Square (PLS) approach, was used to analyse the data. PLS-SEM was preferable on account of its numerous plus points in comparison to first-generation methods. Among the key advantages of PLS are:

- Makes less demands concerning sample size compared to other approaches.

- Do not require normal-distributed input data.

- Can be used for complex structural equation models with many constructs.

- Can manage several dependent and independent variables in a single model.

Besides, PLS as variance-based SEM is favoured since covariance-based SEM assumes that the observed measures possess random error variance and measure specific variance components, which have no theoretical interest and are omitted from the measurement model. Meanwhile, PLS-SEM assumes that the explanation of all the observed measure variance is valuable.

\section{Results and discussion}

\section{Descriptive statistics}

Looking at the respondents' demographic profile, there were $319(82 \%)$ male respondents and 68 (18\%) female respondents. Most had a master's degree $(212,55 \%)$, followed by a bachelor's degree $(147,38 \%)$, and a $\mathrm{PhD}(28,7 \%)$. These 387 respondents were registered PEs with BEM. The total CPD hours accumulated by the PEs in 2013 was more than 50 hours. The mean age of the respondent is 42 years old. There were $215(56 \%)$ of the respondent are working in private sector and $172(44 \%)$ are working in government sector. 


\section{Model testing}

This research employed a two-step method recommended by Anderson and Gerbing (1988) and Chin (2010) to test the conceptual model by first analysing the measurement model, followed by the structural model. The aim was to evaluate the measurements' fit and construct validity prior to evaluating the structural model for path coefficients or associations between the constructs. As such, subsequently, convergent validity and discriminant validity were evaluated to verify construct validity by examining the measurement model outcomes.

\section{Convergent validity}

Cross-loadings, average variance extracted (AVE), and composite reliability (CR) could be evaluated to verify the convergent validity (Table 1). Fornell and Larcker (1981) explained that AVE is the mean-variance extracted for the items loading on a construct and is a summary indicator of convergence. When the AVE value is at least 0.5 , it implies adequate convergent validity, i.e. a latent variable can explain more than half of the variance of its indicators on average (Götz, LiehrGobbers, \& Krafft, 2010). For CR, it is evaluated for reliability, i.e. a measure of convergent validity. As reported by Nunnally and Bernstein (1994), the CR value must be more than 0.7 to guarantee a precise scale. Thus, based on Table 1, the CR values are acceptable, meaning the measures applied have provided satisfactory reliability. According to the factor loadings, AVE, and CR findings, sufficient evidence of convergent validity was demonstrated. To verify the construct validity, discriminant validity findings are presented.

Table 1. Results of the Measurement Model

\begin{tabular}{|c|c|c|c|c|}
\hline Construct & Item & Loadings & $\begin{array}{l}\text { Average Variance } \\
\text { Extracted (AVE) }\end{array}$ & $\begin{array}{c}\text { Composite Reliability } \\
(\mathbf{C R})^{\mathbf{b}}\end{array}$ \\
\hline PCO & PCO_SD_1 & 0.790 & 0.932 & 0.632 \\
\hline \multirow[t]{7}{*}{ (SD) } & PCO_SD_2 & 0.826 & & \\
\hline & PCO_SD_3 & 0.798 & & \\
\hline & PCO_SD_4 & 0.840 & & \\
\hline & PCO_SD_5 & 0.831 & & \\
\hline & PCO_SD_6 & 0.810 & & \\
\hline & PCO_SD_7 & 0.793 & & \\
\hline & PCO_SD_8 & 0.660 & & \\
\hline $\mathrm{PCO}$ & PCO_VD_1 & 0.770 & 0.905 & 0.618 \\
\hline \multirow[t]{5}{*}{ (VD) } & PCO_VD_2 & 0.757 & & \\
\hline & PCO_VD_3 & 0.862 & & \\
\hline & PCO_VD_4 & 0.824 & & \\
\hline & PCO_VD_5 & 0.857 & & \\
\hline & PCO_VD_6 & 0.810 & & \\
\hline \multirow[t]{5}{*}{$\mathrm{CS}$} & CSAT_1 & 0.845 & 0.927 & 0.717 \\
\hline & CSAT_2 & 0.890 & & \\
\hline & CSAT_3 & 0.892 & & \\
\hline & CSAT_4 & 0.778 & & \\
\hline & CSAT_5 & 0.824 & & \\
\hline PWB & PsyWB_1 & 0.662 & 0.900 & 0.630 \\
\hline
\end{tabular}




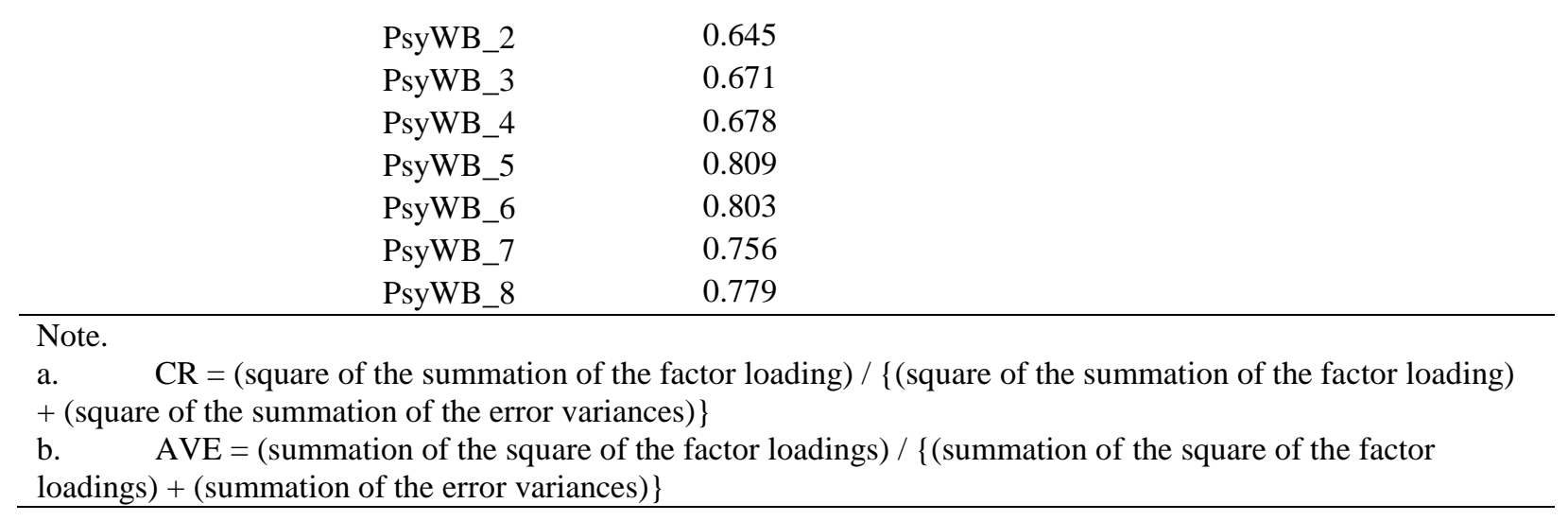

\section{Discriminant validity}

Discriminant validity refers to the "extent to which a construct is truly distinct from other constructs by empirical standards" (Hair et al., 2017). It is reported based on heterotrait-monotrait (HTMT) ratio of correlations criterion in comparison to Fornell-Lacker criterion and cross-loading factors since HTMT performs better than the conventional methods of discriminant validity evaluation (Hair et al., 2017). HTMT is a novel and conservative method in PLS-SEM literature for discriminant validity (Henseler et al, 2015). To attain an acceptable level of discriminant validity, Henseler et al. (2015) suggest an HTMT value of 0.90. An HTMT value of >0.90 implies a lack of discriminant validity, hence, shows that the constructs are conceptually alike. The findings indicated that HTMT was established at HTMT.90; all the constructs had an HTMT score of $<0.90$, thus, demonstrating that all the constructs of this research, namely PCO (SD and VD), CS, and PWB had discriminant validity (see Table 2).

Table 2. Discriminant validity HTMT criterion

\begin{tabular}{llllll}
\hline & Construct & (1) & (2) & (3) & (4) \\
\hline (1) PCO (SD) & & & & & \\
\hline (2) PCO (VD) & 0.696 & & & \\
\hline (3) CS & 0.772 & 0.565 & & \\
\hline (4) PWB & 0.653 & 0.632 & 0.698 \\
\hline
\end{tabular}

\section{Hypotheses testing}

Direct path relationships between the exogenous and endogenous variables are discussed here. Four hypotheses were proposed for the relationship between PCO (SD and VD) and individual WB (CS and PWB). However, only two hypotheses were supported. H2 was accepted, whereby PCO (VD) positively affected CS $(\mathrm{B}=0.484, \mathrm{p}<0.01)$. Similarly, H3 was also accepted in which PCO (SD) positively impacted PWB $(\mathrm{B}=0.184, \mathrm{p}<0.01)$. Meanwhile, the H1 $(\mathrm{P}=-0.004, \mathrm{p}>$ $0.1)$ and $\mathrm{H} 4(\mathrm{~B}=0.060, \mathrm{p}>0.1)$ were not accepted (see Table 3$)$. 
Table 3. Path Coefficient for PCO and Individual WB

\begin{tabular}{llcccc}
\hline No. & Relationship & Path Coefficient $(\boldsymbol{\beta})$ & Std. Error & t-value & Decision \\
\hline H1 & PCO $(\mathrm{SD})--->$ CSAT & -0.004 & 0.044 & 0.093 & Not supported \\
\hline H2 & PCO $(\mathrm{VD})--->$ CSAT & 0.484 & 0.065 & $7.440 * * *$ & Supported \\
\hline H3 & PCO $(\mathrm{SD})--->$ PsyWB & 0.184 & 0.057 & $3.250^{* * *}$ & Supported \\
\hline H4 & PCO(VD)---> PsyWB & 0.060 & 0.072 & 0.834 & Not supported \\
\hline Note: $* * * p<0.01(2.33), * * p<0.05(1.645),{ }^{*} p<0.1(1.28)$ (based on one-tailed test) & \\
\hline
\end{tabular}

\section{Discussion}

The research objective was to determine if PCO (SD and VD) influenced the individual WB (CS and PWB) of Malaysian PEs.

\section{Effect of PCO on CS}

The results revealed that PCO (SD) did not positively affect CS. Conversely, PCO (VD) positively affected CS. Hence, the association between PCO and CS is partially supported. Briscoe et al. (2006) opined that protean career-orientated (SD) people bear responsibility for their success or failure, and in gaining and honing their skills, rather than passively depending on the organisation to offer them a clear career route. Hall et al. (2018) has contended that taking charge of handling one's career progress leads to positive psychological effects, such as career and life satisfaction, and improved self-efficacy and individual WB, if wanted career outcomes are attained. Furthermore, Buil et al. (2019) discovered that people with a proactive nature attained extrinsic career advancement and internal satisfaction with their career. As such, the negative association between PCO (SD) and CS could be because the person's identity is unlikely to be attached to any one organisation (Hall et al., 2018). PEs possess specialist knowledge and expertise. Moreover, they have high hopes and desires concerning their career. Nevertheless, because their key performance areas are designed by the organisation based on the business requirements, it is likely that the PEs in the current research felt that their goals and expectations were unaligned with their employer's. This situation could be caused by the dearth of opportunities to apply the skills they acquired or to fully develop potential abilities. Hence, the PEs were not content with the achievements made in their career. Thus, it was determined that PCO (SD) did not demonstrate a positive impact on CS.

\section{Effect of PCO on PWB}

On the contrary, PWB was positively influenced by PCO (SD). Nonetheless, PWB was not positively influenced by PCO (VD). As such, the relationship between PCO and PWB is partially supported. Briscoe et al. (2006) explained that protean career orientated (VD) people are encouraged to form their career around their values, motives, and requirements, rather than deriving from external standards like outcomes fixed by organisations or society for steering their career. This result could be due to job condition and working environment. It can be assumed that the surveyed PEs are employed in organisations that function in a very competitive market, with projects that highly emphasise on quality, costs, and time. Furthermore, they tend to strain to fulfil 
impractical time limit. Not only that, they face time management issues, whereby sometimes the projects are situated in remote sites or in areas that require extended travel, i.e. will take time away from their loved ones; all these make the PEs' life extra hectic. Hence, engineers experiencing work overload could drain their mental and physical resources and subsequently suffer from health issues or exhaustion. This situation contrasts with protean career (VD) people who follow their own guidance, emphasising the significance of one's requirements, visions, and ambitions and towards the achievement of meaningful outcomes for them. Therefore, this research determined that PCO (VD) did not impart a positive impact on PWB.

\section{Implication of the study}

The first implication of this study is to recommend the organisations to revise PEs' key performance areas to allow them to feel that their goals and expectations align with their employers'. Additionally, the companies must offer opportunities and let the PEs fully apply their gained skills or to improve their abilities to greater potential. Consequently, PEs will experience a higher level of CS.

The second implication of this study is to recommend the organisations to focus on secondary interventions that emphasise on stress management training to reduce the effect of environmental stressors on the PEs. Supervisory courses should raise a person's awareness of his or her level of strain and improve personal coping approaches, for example; relaxation training, time management, and conflict resolution tactics. Such activities will heighten the PEs' PWB to a greater level.

\section{Conclusion}

This research has given empirical support for the theoretical relationships proposed based on the research framework. The associations between PCO (SD and VD) and individual WB (CS and PWB) were validated and confirmed. Furthermore, this study's research framework concurs with Hall's (1976) protean career theory. The similarity is demonstrated by the results that experiences from a person's education, expertise, career goals, and quest for self-fulfilment, can all be integrated as elements of the protean career theory. Protean career orientated individuals are inclined to maintain their freedom and personal growth values. Moreover, these individuals possess higher levels of CS and PWB.

This research has several limitations, and despite those limitations this study is still reliable and valid. One of the limitations is that this study has utilised self-reported data, which necessitated the use of Harman's single factor test to evaluate the potential risk for result interpretation. Secondly, because this is cross-sectional research, outcomes can vary if performed using a longitudinal method. The third limitation is that this study involved only PEs since the requirements for them match Hall's (1976) idea of PCO. Hall has explained that PCO comprises an individual's complete verified experience in education, training, and working in various companies and changes in career fields. Furthermore, Hall (2002) has stated that the protean career approach is based on continuous learning. Future investigations may examine Chartered Accountants (CAs) with the Malaysian Institute of Accountants (MIA). CAs undergo a similar situation as PEs, whereby CA applicants must pass their final examination and possess at least 
three years of working experience as a CA or in a government department, bank, insurance firm, local authority or other commercial, financial, industrial or professional organisations. These requirements concur with the PCO criteria (Hall, 1976). This effort will enhance the generalisability of this present study's results.

Since the key performance of the PEs is structured by the organisations based on the business needs, the organisations should let the PEs be involved in the process of decision making due to their knowledge of science and technology. This approach will make the PEs feel that their goals and expectations are in line with their employers'. As a result, it would increase the PEs' level of CS and PWB.

\section{Acknowledgement}

The author thanks the anonymous referees for critically reviewing this paper and providing suggestions to substantially improve this work.

\section{References}

Anderson, J., \& Gerbing, W. (1988). Structural equation modelling in practice: A review and recommended two stage approach. Psychological Bulletin, 27(1), 5-24.

Baruch, Y., Bhaskar, A. U., \& Mishra, B. (2019). Career dynamics in India: A two-wave study of career orientations and employability of graduates. Personnel Review, 49(3), 825-845.

Berkman, P. L. (1971a). Life stress and psychological well-being: A replication of Langer's analysis in the midtown Manhattan study. Journal of Health and Social Behaviour, 12, 3545.

Berkman, P. L. (1971b). Measurement of mental health in a general population survey. American Journal of Epidemiology, 94, 105-111.

Boo Su-Lyn. (2014, January 1). Survey: doctors, lawyers, engineers are Malaysia's unhappiest workers. The Malaymail Online. Retrieved from https://www.malaymail.com/news/ malaysia/2014/01/01/survey-doctors-lawyers-engineers-are-malaysias-unhappiestworkers $/ 591227$

Briscoe, J. P., \& Hall, D. T. (2006). The interplay of boundary less and protean careers: Combinations and implications. Journal of Vocational Behaviour, 69, 4-18.

Buil, I., Martínez, E., \& Matute, J. (2019). Transformational leadership and employee performance: The role of identification, engagement and proactive personality. International Journal of Hospitality Management, 77, 64-75.

Chin, W. W. (2010). How to write up and report PLS analyses. In Esposito, V., et al. (eds.), Handbook of Partial Least Squares (pp. 655-688). New York: Springer-Verlag.

Diener, E., Lucas, R. E., Oishi, S., Hall, N., \& Donnellan, M. B. (2018). Advances and open questions in the science of subjective well-being. Collabra: Psychology, 4(1), 15.

Fornell, C. G., \& Larcker, D. F. (1981). Evaluating structural equation models with unobservable variables and measurement error. Journal of Marketing Research, 18(1), 39-50.

Greenhaus, J. H., Parasuraman, S., \& Wormley, W. M. (1990). Effects of race on organizational experiences, job performance evaluations, and career outcomes. Academy of Management Journal, 33(1), 64-86. 
Götz, O., Liehr-Gobbers, K., \& Krafft, M. (2010). Evaluation of structural equation models using the partial least squares (PLS) approach. In Handbook of partial least squares (pp. 691711). Springer, Berlin, Heidelberg.

Hall, D. T. (1976). Careers in organizations. Glenview, IL: Scott Foresman.

Hall, D. T. (1996). Protean careers of the 21st century. Academy of Management Perspectives, 10(4), 8-16.

Hall, D. T. (2002). Careers in and out of organizations. Thousand Oaks, CA: Sage Publications.

Hall, D. T. (2004). The protean career: A quarter-century journey. Journal of Vocational Behaviour, 65(1), 1-13.

Hall, D. T., Yip, J., \& Doiron, K. (2018). Protean careers at work: Self-direction and values orientation in psychological success. Annual Review of Organizational Psychology and Organizational Behavior, 5, 129-156.

Hair, J. F., Hult, G. T. M., Ringle, C. M., Sarstedt, M., \& Thiele, K. O. (2017). Mirror, mirror on the wall: a comparative evaluation of composite-based structural equation modeling methods. Journal of the Academy of Marketing Science, 45(5), 616-632.

Henseler, J., Ringle, C. M., \& Sinkovics, R. R. (2009). The use of partial least squares path modeling in international marketing. In R. R. Sinkovics, P. N. Ghauri (Eds.), Advances in International Marketing (pp. 277-320). Bingley, UK: Emerald.

Henseler, J., Ringle, C. M., \& Sarstedt, M. (2015). A new criterion for assessing discriminant validity in variance-based structural equation modeling. Journal of the academy of marketing science, 43(1), 115-135.

Hirschi, A., Jaensch, V. K., \& Herrmann, A. (2017). Protean career orientation, vocational identity, and self-efficacy: An empirical clarification of their relationship. European Journal of Work and Organizational Psychology, 26(2), 208-220.

Hui, B. P., Ng, J. C., Berzaghi, E., Cunningham-Amos, L. A., \& Kogan, A. (2020). Rewards of kindness? A meta-analysis of the link between prosociality and well-being. Psychological Bulletin, 146(12), 1084.

Ismail, H., \& Warrak, A. (2019). The impact of employee well-being on employee retention. International Journal of Business and Management Invention, 8(12), 33-37.

Khan, H., Rehmat, M., Butt, T. H., Farooqi, S., \& Asim, J. (2020). Impact of transformational leadership on work performance, burnout and social loafing: a mediation model. Future Business Journal, 6(1), 1-13.

Kelly Services. (2012). Employment outlook 2012 - Malaysia. Retrieved from http://www.kellyservices.com.my/MY/About-Us/Kelly-Services-Malaysia-EmploymentOutlook-and-Salary-Guide-2012/13/\#.VCpy-PmSwjU

Lambert, L., Lomas, T., van de Weijer, M. P., Passmore, H. A., Joshanloo, M., Harter, J., ... \& Diener, E. (2020). Towards a greater global understanding of wellbeing: A proposal for a more inclusive measure. International Journal of Wellbeing, 10(2), 1-18.

Lingard, H. (2019). Occupational health and safety in the construction sector. In Increasing Occupational Health and Safety in Workplaces. Edward Elgar Publishing.

Mouratidis, K. (2018). Rethinking how built environments influence subjective well-being: A new conceptual framework. Journal of Urbanism: International Research on Placemaking and Urban Sustainability, 11(1), 24-40.

Nunnally, J. C., \& Bernstein, I. H. (1994). Psychometric theory (3rd ed.). New York: McGrawHill. 
Rahim, N. B. (2017). Leveraging the psychological well-being among Malaysian engineers: The role of protean career orientation and career strategy implementation. Jurnal Pengurusan (UKM Journal of Management), 49, 53-65.

Presti, A. L., Manuti, A., \& Briscoe, J. P. (2019). Organizational citizenship behaviors in the era of changing employment patterns: The complementary roles of psychological contracts and protean and boundaryless careers. Career Development International, 24(2), 127-145.

Stauffer, S. D., Abessolo, M., Zecca, G., \& Rossier, J. (2019). French-language translation and validation of the protean and boundaryless career attitudes scales: relationships to proactive personality, career adaptability, and career satisfaction. Journal of Career Assessment, 27(2), 337-357. 